Article

\title{
Study on Collaborative Emission Reduction in Green-House and Pollutant Gas Due to COVID-19 Lockdown in China
}

\author{
Haowei Zhang ${ }^{1}\left(\mathbb{D}\right.$, Xin Ma $^{1,2, * \mathbb{D}}$, Ge Han $^{3} \mathbb{D}$, Hao Xu ${ }^{1}$, Tianqi Shi ${ }^{1}$, Wanqin Zhong ${ }^{1}$ and Wei Gong ${ }^{4}$ \\ 1 State Key Laboratory of Information Engineering in Surveying, Mapping and Remote Sensing, \\ Wuhan University, Wuhan 473079, China; haoweizhang@whu.edu.cn (H.Z.); \\ xiaohao190081@whu.edu.cn (H.X.); shitian@whu.edu.cn (T.S.); 2017301610221@whu.edu.cn (W.Z.) \\ 2 CAS Key Laboratory of Spectral Imaging Technology, Xi'an 710119, China \\ 3 School of Remote Sensing and Information Engineering, Wuhan University, Wuhan 473079, China; \\ udhan@whu.edu.cn \\ 4 School of Electronic Information, Wuhan University, Wuhan 473072, China; weigong@whu.edu.cn \\ * Correspondence: maxinwhu@whu.edu.cn
}

Citation: Zhang, H.; Ma, X.; Han, G.; Xu, H.; Shi, T.; Zhong, W.; Gong, W. Study on Collaborative Emission Reduction in Green-House and Pollutant Gas Due to COVID-19 Lockdown in China. Remote Sens. 2021, 13, 3492. https://doi.org/ $10.3390 /$ rs13173492

Academic Editor: Hanlim Lee

Received: 19 July 2021

Accepted: 31 August 2021

Published: 2 September 2021

Publisher's Note: MDPI stays neutral with regard to jurisdictional claims in published maps and institutional affiliations.

Copyright: (c) 2021 by the authors. Licensee MDPI, Basel, Switzerland. This article is an open access article distributed under the terms and conditions of the Creative Commons Attribution (CC BY) license (https:/ / creativecommons.org/licenses/by/ $4.0 /)$.

\begin{abstract}
In recent years, as China's peaking carbon dioxide emissions and air pollution control projects have converged, scholars have begun to focus on the synergistic mechanisms of greenhouse gas and pollution gas reduction. In 2020, the unprecedented coronavirus pandemic, which led to severe nationwide blockade measures, unexpectedly provided a valuable opportunity to study the synergistic reduction in greenhouse gases and polluting gases. This paper uses a combination of $\mathrm{NO}_{2}$, $\mathrm{O}_{3}$, and $\mathrm{CO}_{2}$ column concentration products from different satellites and surface concentrations from ground-based stations to investigate potential correlations between these monitoring indicators in four Chinese representative cities. We found that $\mathrm{XCO}_{2}$ decreased in March to varying degrees in different cities. It was witnessed that the largest decrease in $\mathrm{CO}_{2},-1.12 \mathrm{ppm}$, occurred in Wuhan, i.e., the first epicenter of COVID-19. We also analyzed the effects of $\mathrm{NO}_{2}$ and $\mathrm{O}_{3}$ concentrations on changes in $\mathrm{XCO}_{2}$. First, in 2020, we used a top-down approach to obtain the conclusion that the change amplitude of $\mathrm{NO}_{2}$ concentration in Beijing, Shanghai, Guangzhou, and Wuhan were $-24 \%,-18 \%,-4 \%$, and $-39 \%$, respectively. Furthermore, the $\mathrm{O}_{3}$ concentration increments were $5 \%, 14 \%, 12 \%$, and $14 \%$. Second, we used a bottom-up approach to obtain the conclusion that the monthly averaged $\mathrm{NO}_{2}$ concentrations in Beijing, Shanghai, and Wuhan in March had the largest changes, changing to $-39 \%,-40 \%$, and $-61 \%$, respectively. The corresponding amounts of changes in monthly averaged $\mathrm{O}_{3}$ concentrations were $-14 \%,-2 \%$, and $9 \%$. However, the largest amount of change in monthly averaged $\mathrm{NO}_{2}$ concentration in Guangzhou was found in December 2020, with a value of $-40 \%$. The change in $\mathrm{O}_{3}$ concentration was $-12 \%$ in December. Finally, we analyzed the relationship of $\mathrm{NO} 2$ and $\mathrm{O} 3$ concentrations with $\mathrm{XCO}_{2}$. Moreover, the results show that the effect of $\mathrm{NO}_{2}$ concentration on $\mathrm{XCO}_{2}$ is positively correlated from the point of the satellite $(\mathrm{R}=0.4912)$ and the point of the ground monitoring stations $(R=0.3928)$. Surprisingly, we found a positive (in satellite observations and $\mathrm{R}=0.2391$ ) and negative correlation (in ground monitoring stations and $\mathrm{R}=0.3333$ ) between $\mathrm{XCO}_{2}$ and the $\mathrm{O}_{3}$ concentrations. During the epidemic period, some scholars based on model analysis found that Wuhan's carbon emissions decreased by $16.2 \%$ on average. Combined with satellite data, we estimate that Wuhan's $\mathrm{XCO}_{2}$ fell by about $1.12 \mathrm{ppm}$ in February. At last, the government should consider reducing $\mathrm{XCO}_{2}$ and $\mathrm{NO}_{2}$ concentration at the same time to make a synergistic reduction.
\end{abstract}

Keywords: COVID-19; $\mathrm{XCO}_{2}$; collaborative reduction; $\mathrm{NO}_{2} ; \mathrm{O}_{3}$

\section{Introduction}

The emergence of the coronavirus disease 2019 (COVID-19) occurred in 30 December 2019 and was declared a global pandemic by the World Health Organization on 11 March 2020 [1]. In response to the COVID-19 outbreak, the China central government had 
gradually implemented severe nationwide lockdown measures since the end of January 2020. These measures placed the society of China on hold, significantly reducing the emissions of pollutants. In the past decade, China had experienced several social pauses, including routine ones, such as the Lunar New Year and special events, such as the Olympic game and G20. However, 2020 is a special year because, in the first half of the year, most cities in China were blockaded, and industrial, power, and transportation activities were minimized. In the second half of the year, China's social activities have gradually returned to normal. Hence, the outbreak of COVID-19 pandemic in 2020 provides an opportunity for the analysis of the carbon cycle and compositional relationship between gases $\left(\mathrm{CO}_{2}\right.$, $\mathrm{NO}_{2}$, and $\mathrm{O}_{3}$ ).

Owing to the outbreak of COVID-19, greenhouse gas emissions have changed significantly, especially in developing countries. Before the pandemic, the concentration of carbon dioxide $\left(\mathrm{XCO}_{2}\right)$ increased by $2 \mathrm{ppm}$ per year over the previous decade, and the global $\mathrm{XCO}_{2}$ increased from $278 \mathrm{ppm}$ (prior to the industrialization era) to $410 \mathrm{ppm}$ in 2020 [2]. However, during the pandemic, Le et al. [3] found that the daily global $\mathrm{CO}_{2}$ emissions decreased by $-17 \%$ by early April 2020 relative to the mean 2019 levels. Zhu et al. [4] found an abrupt $8.8 \%$ decrease in global $\mathrm{CO}_{2}$ emissions $\left(-1551 \mathrm{MtCO}_{2}\right)$ in the first half of 2020 compared to the same period in 2019. The International Energy Agency (IEA) used monthly projections of fossil fuel energy demand and estimated a $-5 \%$ decline in global $\mathrm{CO}_{2}$ emissions from January to April 2020, compared to the same period in 2019 [5]. Moreover, the impacts of lockdown in different regions on air quality were observed [6-10]. Dantas et al., considered the consequences of partial lockdown on air quality and obtained the conclusion that PM10 level was reduced to a low level, and $\mathrm{NO}_{2}$ decreased because of the lockdowns [11]. Sahin et al., explored the consequences of weather on COVID-19 pandemic and concluded that wind showed a positive correlation with COVID-19 cases [12]. Ogen et al., studied the outcome of $\mathrm{NO}_{2}$ on COVID-19 mortality and concluded that long-term exposure to $\mathrm{NO}_{2}$ increased fatalities because of COVID-19 [13]. Xie and Zhu explored the effect of temperature on COVID-19 transmission and found a negative relationship between temperature and increased COVID-19 transmission when the temperature was between $16.8^{\circ} \mathrm{C}$ and $27.4^{\circ} \mathrm{C}$ [4]. Shi et al., examined the outcome of temperature on COVID-19 transmissions and showed that temperature had a positive linear association with COVID-19 cases when the temperature was lower than $3^{\circ} \mathrm{C}$ [14]. These studies provided a scientific basis for the study of the relationship between air pollutants and polluting gases and effective ideas for the prevention and control of pollutants and polluting gases.

These studies analyzed changes in trace gases, emissions, and temperature during the epidemic period in 2020 from different perspectives, but the analysis of trace gas concentration changes in 2020 is rare. Few scholars have studied the $\mathrm{XCO}_{2}$ changes [15-22], meanwhile, the government implemented lockdowns caused by the epidemic has provided us with a good opportunity for this analysis. We have accomplished several works in this article as follows. Firstly, we analyzed changes in monthly averaged concentrations of $\mathrm{CO}_{2}, \mathrm{NO}_{2}$, and $\mathrm{O}_{3}$ in Beijing, Shanghai, Wuhan, and Guangzhou. For Beijing, Shanghai, Guangzhou, and Wuhan, the results suggested that the amounts of changes in $\mathrm{XCO}_{2}$ were $0.13,-0.99,-0.89$, and $-1.12 \mathrm{ppm}$ in February, respectively. The concentrations of $\mathrm{NO}_{2}$ and $\mathrm{O}_{3}$ changed by $-24 \%$ and $5 \%,-18 \%$ and $14 \%,-4 \%$ and $12 \%,-39 \%$ and $14 \%$, respectively, by comparing data in February 2019 with the Sentinel-Satellite- 5 data. Furthermore, for Beijing, Shanghai, Guangzhou, and Wuhan, with regard to the ground monitoring network data, the largest amounts of changes in monthly averaged concentrations of $\mathrm{NO}_{2}$ and $\mathrm{O}_{3}$ were $-39 \%$ and $14 \%,-40 \%$ and $-2 \%,-61 \%$ and $9 \%$ in February, respectively. However, for Guangzhou, it is in December, and the decrease in $\mathrm{NO}_{2}$ and $\mathrm{O}_{3}$ is $-40 \%$ and $-12 \%$, respectively. Secondly, we have evaluated the relationship between the variation of $\mathrm{XCO}_{2}$ and the variation of $\mathrm{NO}_{2}$ and $\mathrm{O}_{3}$. We found the effect of $\mathrm{NO}_{2}$ concentration on $\mathrm{XCO}_{2}$ is positively correlated from the point of the satellite $(\mathrm{R}=0.4912)$ and the point of the ground monitoring stations $(\mathrm{R}=0.3928)$. Furthermore, we found that $\mathrm{XCO}_{2}$ and $\mathrm{O}_{3}$ are correlated, with a correlation coefficient of 0.2391 (from satellite observations) and -0.3333 
(from ground monitoring stations). Therefore, from the point of promoting the reduction in $\mathrm{XCO}_{2}$ in atmosphere, the contribution of $\mathrm{NO}_{2}$ concentration is greater than that of $\mathrm{O}_{3}$ concentration. Moreover, the government should consider reducing $\mathrm{XCO}_{2}$ and $\mathrm{NO}_{2}$ concentration at the same time to make a synergistic reduction. The remaining parts of this work are arranged as follows. The data and method we used are described in Section 2. The main results and discussions are demonstrated in Section 3. Finally, we conclude the whole study in Section 4.

\section{Materials and Methods}

\subsection{Study Area}

In this paper, four locations were selected: Beijing, Shanghai, Guangzhou, and Wuhan. The main reasons are as follows. First, the Beijing, Shanghai, and Guangzhou are international cities and are located at different latitudes [10], whereas Wuhan is the first epicenter of COVID-19 around the world and is the most important city in central China in terms of economy, education, innovation, and industry; the climatic characteristics of these metropolitan areas are quite different. Therefore, these cities provide good conditions for studying changes in $\mathrm{CO}_{2}, \mathrm{NO}_{2}$, and $\mathrm{O}_{3}$ concentrations amid the COVID-19 lockdown in different regions. We show the spatial location distribution of the research area in detail in Figure 1.

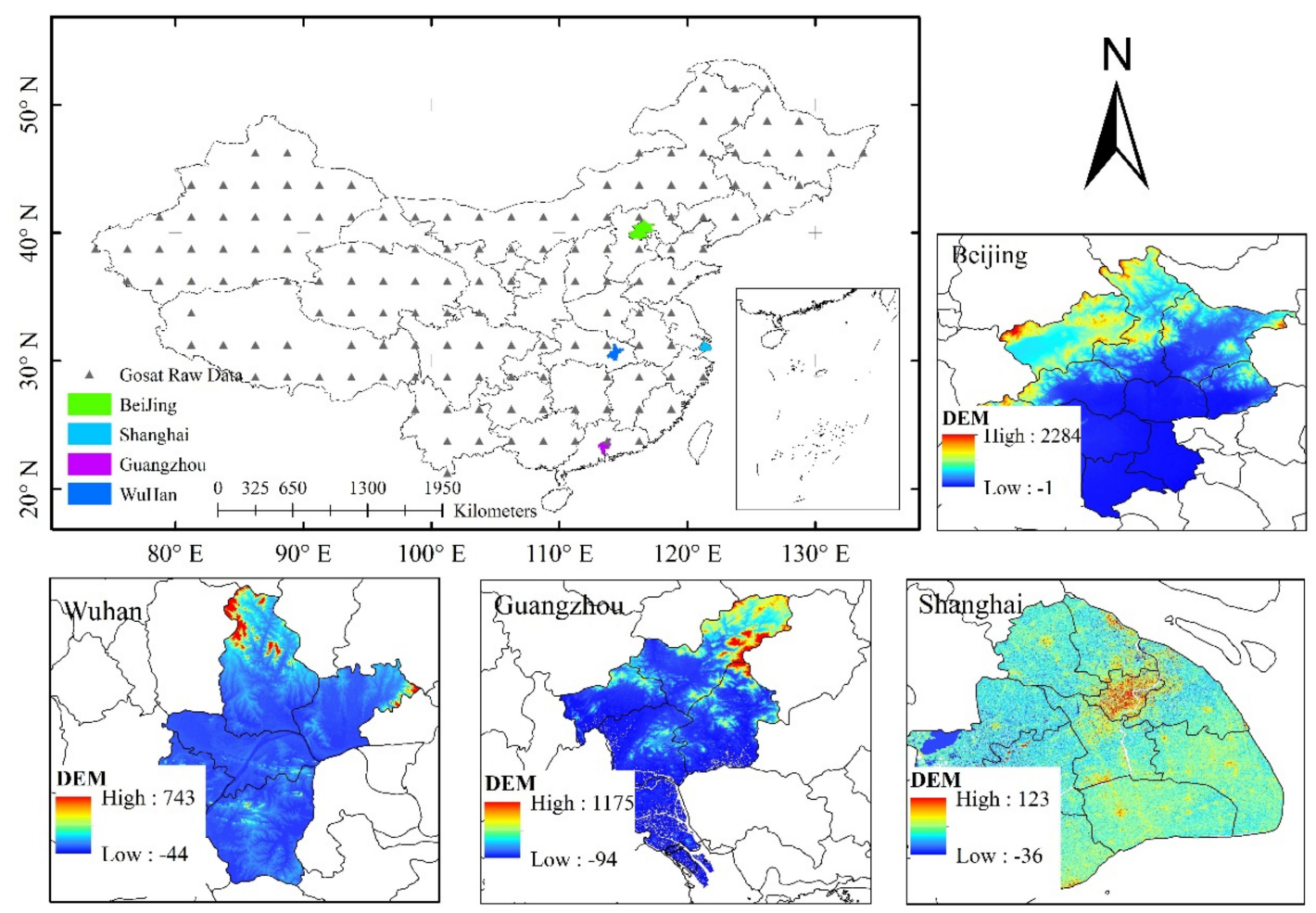

Figure 1. Map of the study area.

\subsection{Datasets}

\subsubsection{Remotely Sensed Products}

We analyzed changes in the monthly averaged concentrations of $\mathrm{CO}_{2}, \mathrm{NO}_{2}$, and $\mathrm{O}_{3}$ in 2020. For $\mathrm{NO}_{2}$ and $\mathrm{O}_{3}$ data, we used a Sentinel-5 Precursor offline level 3 product [23], which was obtained from the Google Earth Engine platform [24]. The Sentinel-5 Precursor is a satellite launched on 13 October 2017 by the European Space Agency to monitor air pollution. Owing to the incomplete data of $\mathrm{O}_{3}$ and $\mathrm{NO}_{2}$ in 2018, we used data from January 2019 to December 2020. 
As for $\mathrm{CO}_{2}$ data, the GOSAT_FTS_L3_V2.95 data of bias-corrected [25] from January 2016 to December 2020 were selected. The Gosat and Gosat-2 satellites have been in orbit since 2009 and 2018, respectively, and their global coverages holds the potential to reveal new information about the carbon cycle by top-down atmospheric inversion methods combined with column-average $\mathrm{CO}_{2}$ retrievals. The GOSAT satellite embarks the Thermal and Near-infrared Sensor for carbon Observation (TANSO) to characterize the column abundances of $\mathrm{CO}_{2}$ and $\mathrm{CH}_{4}$. Six of the seven data channels of this sensor operate in the near-infrared part of the solar spectrum, so this device cannot be used whenever the planet reflects little solar light, i.e., in polar regions during winter. For additional information on that instrument, please consult this website [26]. Besides, a suite of passive remote sensing satellites can measure the reflected sunlight spectra in the infrared region over the globe. These measured spectra are used to retrieve the column-averaged $\mathrm{CO}_{2}$ concentration $\left(\mathrm{XCO}_{2}\right)$ (e.g., GOSAT, GOSAT-2, OCO-2, OCO-3, and TanSat). However, the interference of clouds and aerosols in $\mathrm{XCO}_{2}$ retrieval often results in sparse spatial and temporal coverage. Therefore, there is no data for these latitudinal regions in China, namely latitudes higher than $48.7^{\circ} \mathrm{N}$ in December, higher than $51.2^{\circ} \mathrm{N}$ in November and higher than $51.3^{\circ} \mathrm{N}$ in January.

\subsubsection{Ground Monitoring Data}

To further explore the relationship of changes in monthly averaged $\mathrm{NO}_{2}$ and $\mathrm{O}_{3}$ concentrations with $\mathrm{XCO}_{2}$, a bottom-up approach was adopted for analysis, and ground monitoring data were used. The China Air Quality Network includes daily averaged gas concentration changes in China [27]. Hence, along with remotely sensed data, the ground monitoring data were also included in this work. In addition, to evaluate the accuracy of the monthly averaged $\mathrm{CO}_{2}$ concentration data from our algorithm, we used the TCCON (Hefei site) data. The Total Carbon Column Observing Network (TCCON) $[28,29]$ is a network of ground-based Fourier transform spectrometers that record direct solar spectra in the near-infrared spectral region. From these spectra, accurate and precise column-averaged abundances of $\mathrm{CO}_{2}$ are retrieved and reported. For the period of this data and the purpose for which the data are used, we explain in detail in Table 1.

Table 1. Overview of data.

\begin{tabular}{ccc}
\hline Data Type & Temporal Interval & Use Type \\
\hline GOSAT_FTS_L3_V2.95 & 201601-202012 & $\begin{array}{c}\text { Analyze changes in } \mathrm{CO}_{2} \text { concentration } \\
\text { To evaluate the accuracy of the monthly } \\
\text { averaged } \mathrm{CO}_{2} \text { concentration data from } \\
\text { our algorithm }\end{array}$ \\
$\begin{array}{c}\text { Sentinel-5_Offline_L3_ } \mathrm{NO}_{2} \\
\text { and Sentinel-5_Offline_L3_O }\end{array}$ & 201601-201612 & $\begin{array}{c}\text { To analyze the effects of } \mathrm{NO}_{2} \text { and } \mathrm{O}_{3} \\
\text { concentrations on change in } \mathrm{XCO}_{2} \text { with } \\
\text { top-down }\end{array}$ \\
$\begin{array}{c}\mathrm{NO}_{2} \text { and } \mathrm{O}_{3} \text { from China Air } \\
\text { Quality Network }\end{array}$ & 201901-202012 & $\begin{array}{c}\text { To analyze the effects of } \mathrm{NO}_{2} \text { and } \mathrm{O}_{3} \\
\text { concentrations on change in } \mathrm{XCO}_{2} \text { with } \\
\text { bottom-up }\end{array}$ \\
\hline
\end{tabular}

\subsection{Analysis Method}

This paper mainly adopted a comparative approach for analyzing the impact of the COVID-19 lockdown on the atmospheric environment in 2020. Hence, our work mainly focused on the following four points in detail. Firstly, given the bias-corrected GOSAT_FTS_L3_V2.95 productions are discrete point data, we used the empirical bayesian kriging (EBK) interpolation theory to fill the data gaps in the study area [30]. Additionally, the EBK method is a ground statistical interpolation method that automatically performs the most difficult steps in building an effective kriging model [31-33]. The EBK method differs from other kriging methods in illustrating the error introduced by estimating a basic semivariogram. Other kriging methods underestimate the standard error of prediction 
because they do not consider the uncertainty involved in this semivariogram estimation [33]. For $\mathrm{NO}_{2}$ and $\mathrm{O}_{3}$ planar product data, we directly used it. Second, for GOSAT and GOSAT-2 satellites and ground monitoring data in 2016, 2017, 2018, and 2019, we obtained standard curves using locally weighted regression (LWR). The LWR is a nonparametric method. In each prediction of new samples, the adjacent data will be retrained to obtain new parameter values, to avoid under-fitting and reduce the interference of distant data effectively. Third, we analyzed change in $\mathrm{XCO}_{2}$ by comparing the standard curve data in 2020. To analyze the concentration influence of $\mathrm{NO}_{2}$ and $\mathrm{O}_{3}$ on the change in $\mathrm{CO}_{2}$ concentration, we used the top-down method and bottom-up method, respectively. The investigation of local processes, construction of models, and extrapolation with spatial data to larger scales has been called the "bottom-up" approach. The "top-down" approach aims to obtain data values over a large area in a short period of time without knowing the underlying details of the data caused by subtle scale changes. Therefore, the top-down and bottom-up approaches are thus complementary, and we comprehensively analyzed the influences of $\mathrm{NO}_{2}$ and $\mathrm{O}_{3}$ concentrations on change in $\mathrm{XCO}_{2}$ with satellite data and ground monitoring data in a "multiple constraint" approach.

\section{Results and Discussions}

\subsection{Spatial Distribution of Remotely Sensed $\mathrm{CO}_{2}$ Concentrations}

GOSAT and GOSAT-2 provide passive inversion data and are particularly vulnerable to cloud, aerosol, latitude, and dark night constraints, which cause loss of satellite observation data. We utilized GOSAT_FTS_L3_V2.95 productions, as described in Section 2, and completed the conversion of the GOSAT and GOSAT-2 data points to the surfaces by adopting empirical bayesian kriging (EBK) theory. The data of vacant areas in the study area were filled. Figure 2 shows the interpolated data by using only EBK theory in 2020 . Given that the atmospheric environment in China is complex and GOSAT and GOSAT-2 are particularly sensitive to aerosols and clouds, the data gaps in eastern and central China were large. Moreover, the Hainan and Taiwan Provinces as well as the South China Sea are not marked on the local maps in Figure 2. Fortunately, in this case, we were able to use the EBK theory to complete the monthly averaged spatial interpolation on the $0.25^{\circ}$ grid.

The Total Carbon Column Observing Network (TCCON) is a network of ground-based Fourier transform spectrometers recording direct solar spectra in the near-infrared spectral region [26]. From these spectra, accurate and precise column-averaged abundances of $\mathrm{CO}_{2}$ are retrieved and reported. In addition, we evaluated the accuracy by combining TCCON site (Hefei [29]) data in 2016 (as shown in Figure 3), and the coefficient of determination $\left(R^{2}\right)$ and root-mean-square error (RMSE) were 0.915 and 0.654 , respectively. 

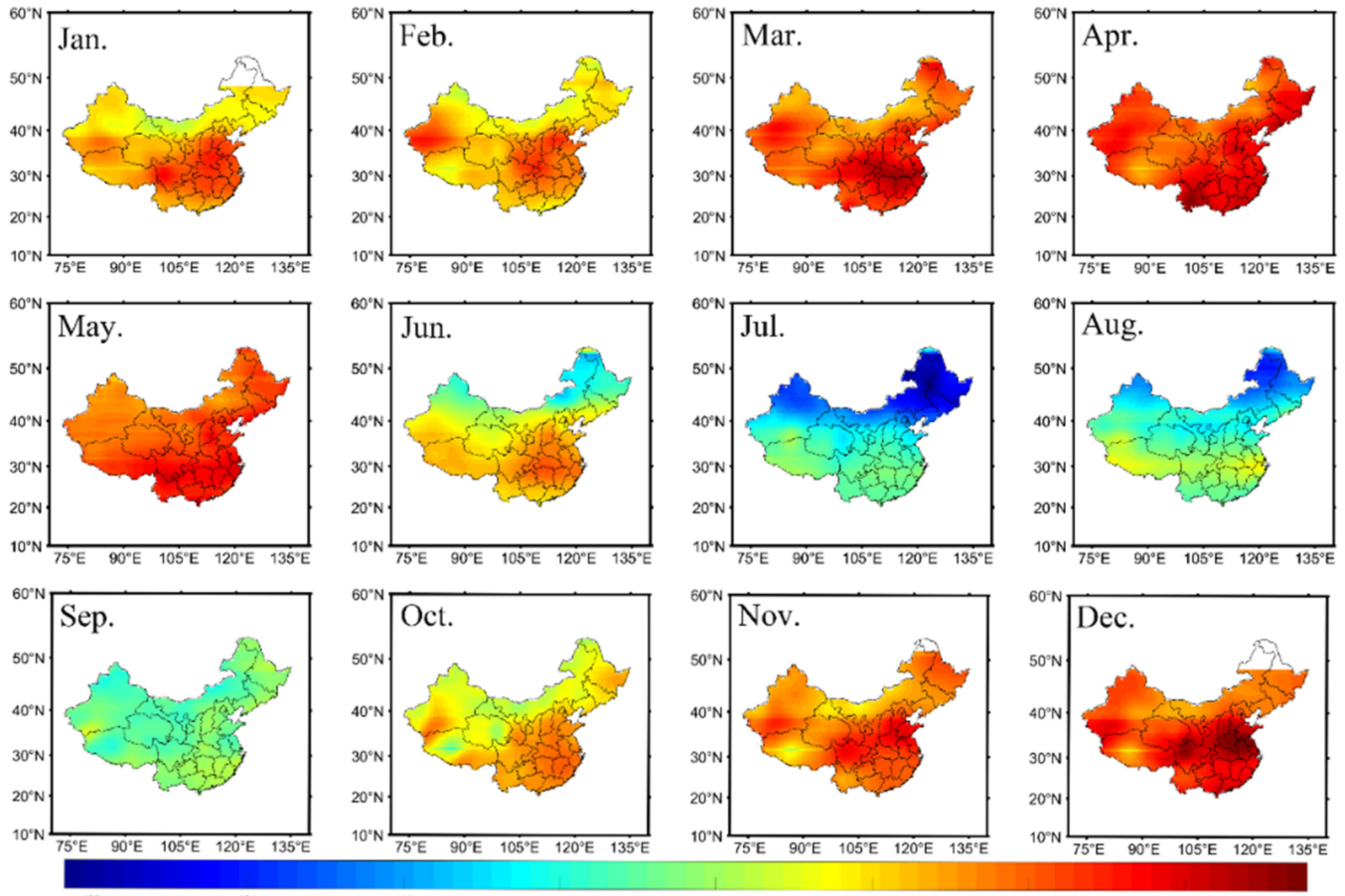

Figure 2. Monthly averaged $\mathrm{XCO}_{2}$ concentrations from the predicted values for each grid $\left(0.25 \times 0.25^{\circ}\right)$ in 2020 for mainland China. Due to lack of data over the ocean, the Hainan and Taiwan Provinces as well as the South China Sea are not marked on the local maps. And due to the lack of data, there were gaps in the forecast data for November, December, and January.

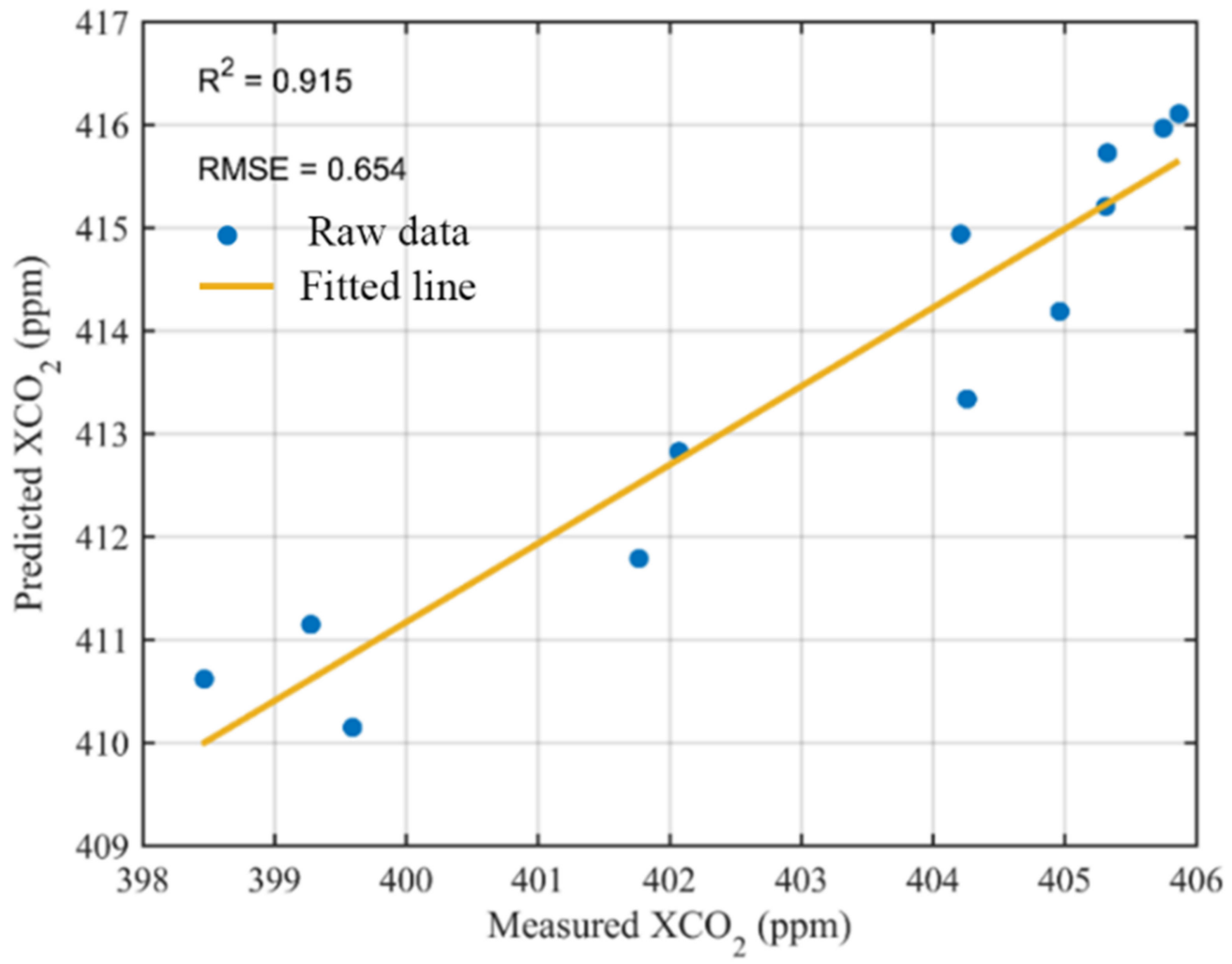

Figure 3. Verification results of the $\mathrm{CO}_{2}$ interpolation and TCCON data. The yellow line represents the results of the local weighted regression, the measured and predicted $\mathrm{XCO}_{2}$ represents the observed TCCON data and interpolated data, respectively. 


\subsection{Analysis of Changes in $\mathrm{XCO}_{2}$}

Multiple pixels in the sub-study areas were found because the spatial resolution of the products after interpolation was $0.25^{\circ}$. To evaluate the influence of COVID-19 on the $\mathrm{XCO}_{2}$ of each month in 2020, we matched the five-year $\mathrm{XCO}_{2}$ curve to a scale from 2016 to 2020. First, we set the $2019 \mathrm{XCO}_{2}$ data as a baseline and then unified the 2016, 2017, 2018, and $2020 \mathrm{XCO}_{2}$ to the 2019 baseline by revising the annual $\mathrm{XCO}_{2}$ curve increments. This increment was revised using the annual $\mathrm{XCO}_{2}$ curve increments at Waligura stations from global atmosphere watch in China [34]. By performing local weighted regression on all grid $\mathrm{XCO}_{2}$ changes in the current sub-study, the grid scale $\mathrm{XCO}_{2}$ changes were converted to city scale. Because cities vary in development and geographical location, we added a city increment for each city relate to the annual $\mathrm{XCO}_{2}$ curve increments. We use the standard deviation as the city increment, which is the difference between the $\mathrm{XCO}_{2}$ for each month in 2020 and the trend line $\mathrm{XCO}_{2}$. We studied the change in the monthly averaged $\mathrm{XCO}_{2}$ of the city. The image resolution was 0.25 degree after interpolation, and the average amount of change in several pixels contained in each city was obtained.

Then, we tested the revised $\mathrm{XCO}_{2}$ data in 2020 using the Kruskal-Wallis test. The Kruskal-Wallis test is a nonparametric test of three or more datasets. It is used to test the consistency of the null hypothesis and its alternative hypothesis about differences between at least two samples of a population function distribution. A standard is usually used in evaluating significance. The $P$ value is 0.05 . If the $P$ value is less than or equal to 0.05 , difference between two samples are considered statistically significant; otherwise, they are considered insignificant. A significant difference between the two samples indicated that the $\mathrm{XCO}_{2}$ data in 2020 and local weighted regression $\mathrm{XCO}_{2}$ from 2016 to 2019 were independent. That is, when the $P$ value in Figure 4 is less than 0.05 , it indicates that the prevention and control measures during this epidemic period caused this change. For the period from February to May in Wuhan, the $P$ value was less than 0.05 . For the period from March to April in Beijing, the $P$ value is also less than 0.05, and for Shanghai and Guangzhou in February, the $P$ value is also less than 0.05 . The above results show that the monthly averaged $\mathrm{XCO}_{2}$ in 2020 changed relative to the trend line data; the variation in $\mathrm{XCO}_{2}$ concentration is shown in Figure 5.

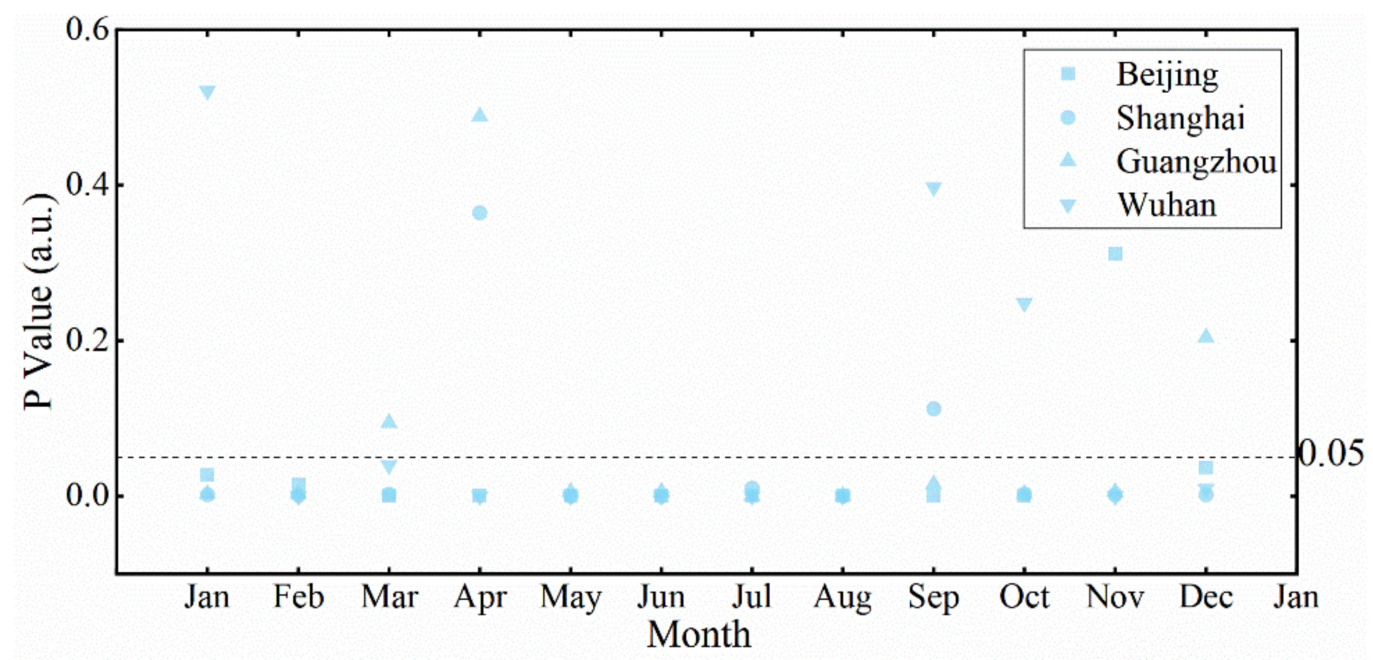

Figure 4. Calculated $P$ values of each month in the study area by using the Kruskal-Wallis test. 

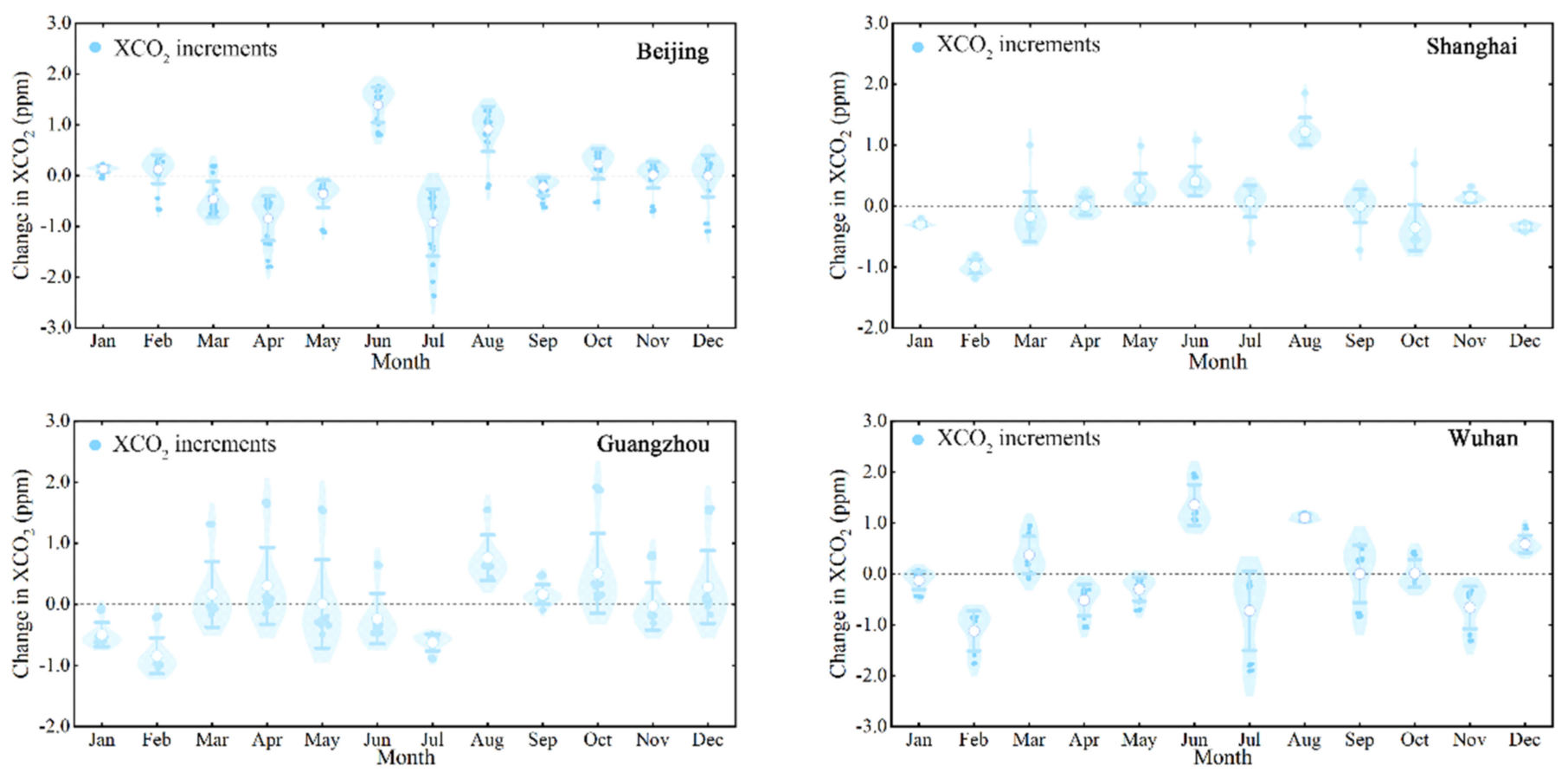

Figure 5. $\mathrm{XCO}_{2}$ change in each month in 2020. The blue dot represents the $\mathrm{XCO}_{2}$ increments in each grid $\left(0.25^{\circ}\right)$ in the corresponding study area. Open points represent mean value, whereas the whiskers mark the standard deviation. The plotted violins represent the kernel density estimation of the probability density function for each sample.

Due to the impact of COVID-19 in Beijing, Shanghai, Guangzhou, and Wuhan, Figure 5 shows the monthly averaged $\mathrm{XCO}_{2}$ changes values in 2020. The Chinese government has taken lockdown measures in most Chinese cities from the end of January to early April. Therefore, the $\mathrm{XCO}_{2}$ fluctuates relatively sharply during the period. We found the amounts of changes in $\mathrm{XCO}_{2}$ were $0.13,-0.99,-0.90$, and -1.12 ppm in February, for Beijing, Shanghai, Guangzhou, and Wuhan. Then $\mathrm{XCO}_{2}$ continued to decrease from March to May in Beijing. In Shanghai and Guangzhou, both international cities, $\mathrm{XCO}_{2}$ gradually returned to normal levels in April and March, respectively.

Notably, the trend of $\mathrm{XCO}_{2}$ in June, July, and August varied between the coastal cities (Shanghai and Guangzhou) and the inland cities (Beijing and Wuhan). Furthermore, this difference is a combination of effects resulting from seasonal impact weights and the corresponding intensification of industrial emissions. The weight of the seasonal impact of $\mathrm{XCO}_{2}$ gradually increased in June, July, and August. The weight of seasonal influence represents the enhancement of $\mathrm{CO}_{2}$ absorption capacity from surface vegetation. Besides, by analyzing the change in $\mathrm{NO}_{2}$ concentration from June to August in Figure 6, we found that the corresponding industrial emissions of Beijing and Wuhan gradually increased in the three months. Therefore, under the combined action of these two factors, the amounts of changes in $\mathrm{XCO}_{2}$ in June, July, and August in Beijing were 1.54, -0.92 , and $0.90 \mathrm{ppm}$, respectively. In addition, the amounts of changes in $\mathrm{XCO}_{2}$ in Wuhan were $1.30,-0.70$, and $1.1 \mathrm{ppm}$. 

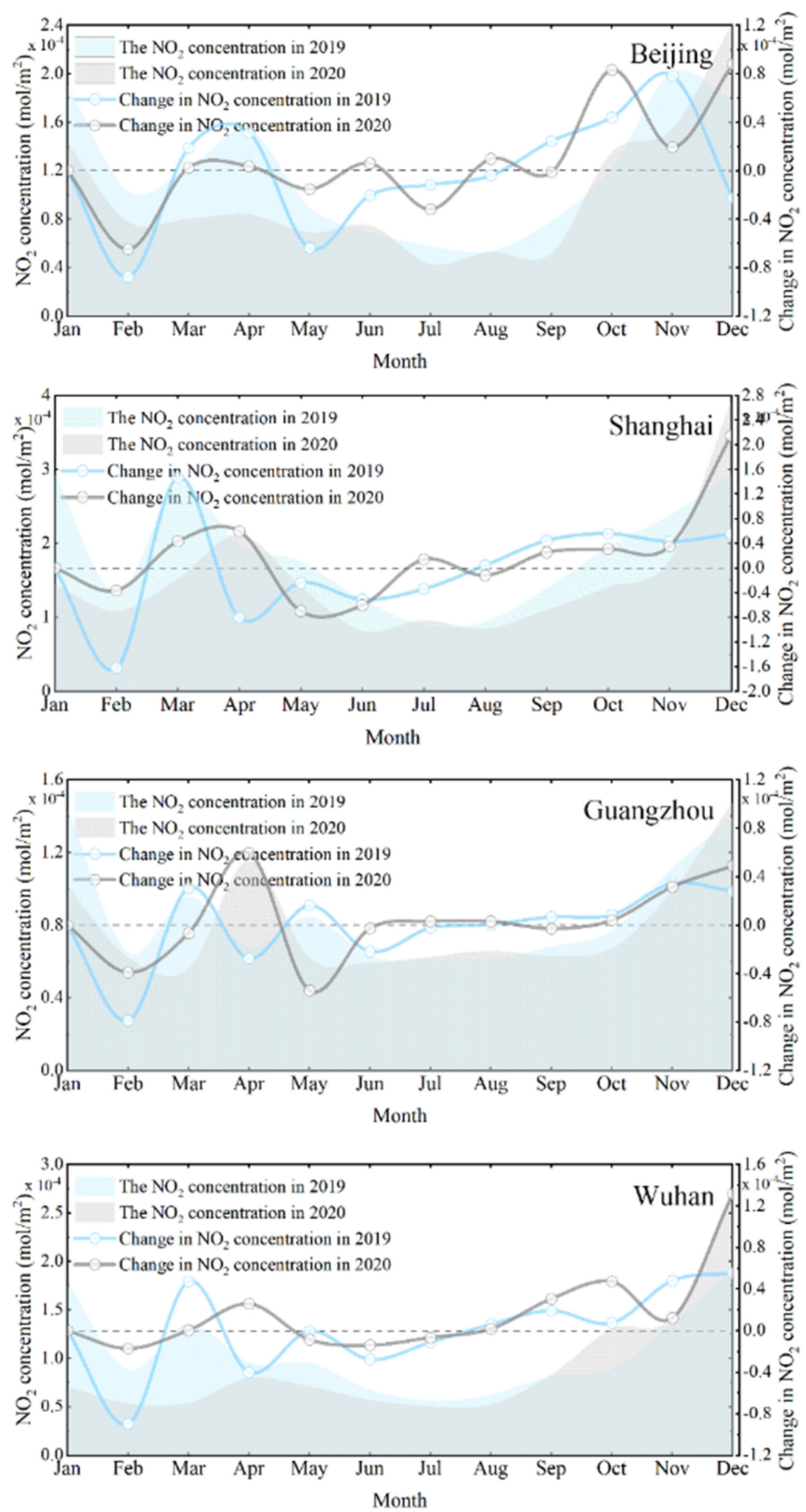
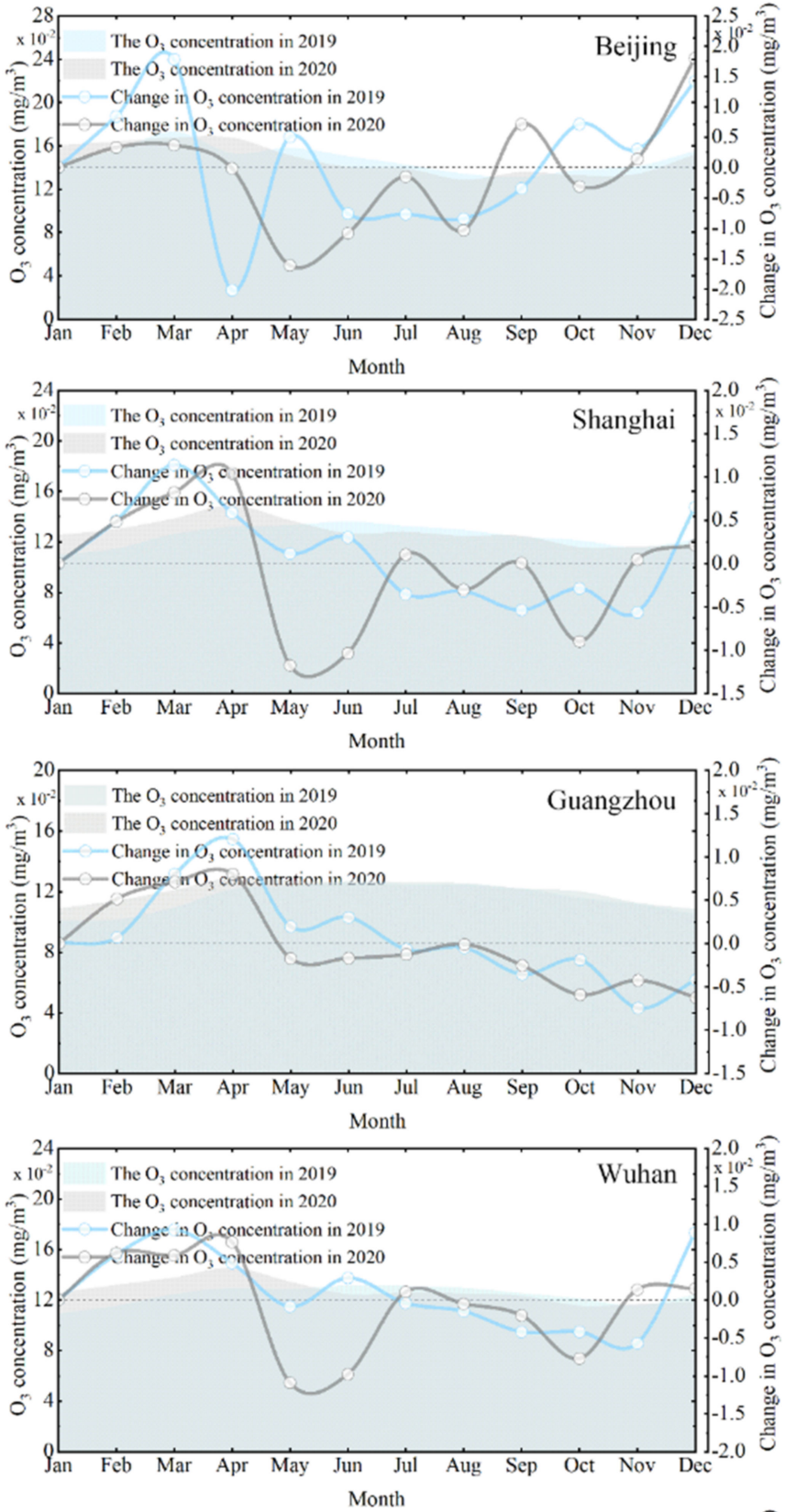

Figure 6. Concentration and increment change in $\mathrm{NO}_{2}$ and $\mathrm{O}_{3}$ in 2019 and 2020, respectively. The blue and gray areas in the figure represent the monthly averaged concentrations of $\mathrm{NO}_{2}$ and $\mathrm{O}_{3}$ in 2019 and 2020, respectively. Moreover, the blue and gray curve represents the monthly averaged increase in $\mathrm{NO}_{2}$ and $\mathrm{O}_{3}$ in 2019 and 2020, respectively. This increment represents the concentration increase in the current month compared to the previous month, which corresponds to the axis on the right.

For coastal cities of Shanghai and Guangzhou, there are some differences in the change in $\mathrm{CO}_{2}$ concentration. Although Shanghai and Guangzhou are coastal cities, the latitude of Guangzhou is lower than that of Shanghai, and this condition increases the absorption effect of $\mathrm{XCO}_{2}$ brought by season in Guangzhou. In addition, Guangzhou's geographical proximity to Zhaoqing, an industrial city, increases the dispersion of $\mathrm{XCO}_{2}$ in Guangzhou. In this case, the amounts of changes in $\mathrm{XCO}_{2}$ in June, July, and August were $-0.29,-0.57$, and $0.49 \mathrm{ppm}$. However, as the engine of China's economy, Shanghai's industrial recovery speed is extremely fast $\left(\mathrm{XCO}_{2}\right.$ was fully recovered in April, and the $\mathrm{XCO}_{2}$ in May and June showed an upward trend), and industrial emission intensity is increasing. Therefore, 
under the action of increasing seasonal factors, the $\mathrm{XCO}_{2}$ in June, July, and August showed a gradually increasing trend, with values of $0.41,0.08$, and $1.20 \mathrm{ppm}$.

In September and October, the amounts of changes in $\mathrm{XCO}_{2}$ remained $0 \mathrm{ppm}$ in the inland cities of Beijing and Wuhan. For the coastal cities of Guangzhou and Shanghai, the amounts of changes in $\mathrm{XCO}_{2}$ remained $0 \mathrm{ppm}$ in September, but the amounts of changes in $\mathrm{XCO}_{2}$ were 0.57 and $-0.35 \mathrm{ppm}$ in October, respectively. This phenomenon is related to the prevention and control measures of the local government [35-37] and the industrial structure of the surrounding cities. In November and December, the Chinese government strengthened control measures to prevent the recurrence of the epidemic in winter. Second, the annual curve of $\mathrm{XCO}_{2}$ are the interval of the increase in $\mathrm{XCO}_{2}$ in November and December. Therefore, under the action of the above two factors, the amounts of changes in $\mathrm{XCO}_{2}$ were $0 \mathrm{ppm}$ in Beijing and Guangzhou. However, in Wuhan and Shanghai, the amounts of changes in $\mathrm{XCO}_{2}$ fluctuated in November and December. The first outbreak of the epidemic in Wuhan, China lasted for a long time and had a significant effect on reducing the production vitality of some industrial companies in Wuhan [38]. The Shanghai's $\mathrm{XCO}_{2}$ dropped in December because the Shanghai government had to strengthen the prevention and control of the epidemic after local cases emerged [37,39].

The epidemic affected Wuhan mainly in two periods, from January to May and from November to December. In Guangzhou and Shanghai, the effects were mainly from January to March and in December. Beijing is the political and economic center of China; its $\mathrm{XCO}_{2}$ were affected by the outbreak from March to May, and the significant change occurred in March. In addition, the greater variation of $\mathrm{XCO}_{2}$ was due to the seasonal effects in June, July, and August.

\subsection{Analysis of Changes in the Concentration of Gases $\left(\mathrm{NO}_{2}\right.$ and $\left.\mathrm{O}_{3}\right)$ from Top-Down and Down-Top, Respectively}

Given that only 2019 and 2020 had complete data, we directly used Sentinel-5 Premonitory Offline Level 3 products. We obtained the monthly averaged $\mathrm{NO}_{2}$ and $\mathrm{O}_{3}$ data by determining the mean value in each study area. In this section, we compared the data detected in 2019. Figure 6 show the specific monthly averaged concentration $\left(\mathrm{NO}_{2}\right.$ and $\left.\mathrm{O}_{3}\right)$ and increment changes in 2019 and 2020. The monthly averaged increment represents the increase in concentration from the previous month and to the current month.

Transport and industrial production are the main sources of $\mathrm{NO}_{\mathrm{X}}$ emissions, and thus the monthly averaged $\mathrm{NO}_{2}$ concentration changes can reflect the cessation of productivity during the epidemic and the recovery of productivity after the epidemic. Figure 6 shows the concentration and increment change in $\mathrm{NO}_{2}$ and $\mathrm{O}_{3}$ in 2019 and 2020, respectively. In Figure 6, the curve of $\mathrm{NO}_{2}$ concentration increment fluctuates mainly from February to May in 2019 and 2020, consistent with the duration of the epidemic released by the Chinese authorities [40]. During the epidemic outbreak, industrial emissions and traffic decreased to a large extent in all parts of China. In the atmosphere, compared with that in February 2019, the amplitude of $\mathrm{NO}_{2}$ concentration in 2020 in Beijing, Shanghai, Guangzhou, and Wuhan decreased by $2.52 \times 10^{-5}, 2.32 \times 10^{-5}, 0.25 \times 10^{-5}$, and $3.46 \times 10^{-5} \mathrm{~mol} / \mathrm{m}^{2}$, respectively. The percentage decrease was $24 \%, 18 \%, 4 \%$, and $39 \%$, respectively. Then, in March, April, and May, the monthly averaged increase in $\mathrm{NO}_{2}$ concentration in 2020 was smaller than that in 2019. Change in $\mathrm{NO}_{2}$ concentration recovered to the 2019 level from June to December, indicating that the epidemic in China has been brought under control and industrial production has recovered [40]. From February to June 2020, the $\mathrm{NO}_{2}$ concentration decreased, but the $\mathrm{O}_{3}$ concentration showed an increasing trend (Figure 6). Specifically, in February 2020, $\mathrm{O}_{3}$ concentration increments in Beijing, Shanghai, Guangzhou, and Wuhan were $0.851 \times 10^{-2}, 1.55 \times 10^{-2}, 1.24 \times 10^{-2}$, and $1.66 \times 10^{-2} \mathrm{~mol} / \mathrm{m}^{3}$, respectively. The decrease percentage was $5 \%, 14 \%, 12 \%$, and $14 \%$, respectively. In addition, the increment change in $\mathrm{O}_{3}$ concentration was extended to June, a month longer than the increment change time of $\mathrm{NO}_{2}$ concentration. Similarly, in March, April, May, and June, the monthly averaged increase in $\mathrm{O}_{3}$ concentration in 2020 was smaller than that in 2019. From July to 
December in 2020, the $\mathrm{O}_{3}$ concentration increment in each region gradually returned to the normal state.

To further analyze the effect of $\mathrm{NO}_{2}$ and $\mathrm{O}_{3}$ concentration on the change in $\mathrm{XCO}_{2}$, we analyzed the daily averaged data of monitoring stations in the ground cities. Given that China's big events are held according to traditional holidays (Spring Festival and National Day), we matched the 2020 and 2019 time series according to the Lunar New Year. We obtained monthly averaged ground station data by averaging the daily averaged data of monitoring stations in the ground cities. Figure 7 shows the daily averaged and monthly averaged concentration change in $\mathrm{NO}_{2}$ and $\mathrm{O}_{3}$ in 2019 and 2020, respectively. We learned that the daily averaged $\mathrm{NO}_{2}$ concentration in Beijing decreased in 11 February. The daily averaged and monthly averaged concentrations in 2020 were lower than those in 2019 from 11 February to 31 October because the prevention and control measures were strict in Beijing. The monthly averaged distribution of $\mathrm{NO}_{2}$ concentrations began to decline in February, briefly returned to normal in November, and began to decline again in December. The largest annual decline in March was $15.56 \mu \mathrm{g} / \mathrm{m}^{3}$ in Beijing. The percentage decline was $39 \%$. $\mathrm{NO}_{2}$ concentration decreased, whereas $\mathrm{O}_{3}$ concentration increased by $4.23 \mu \mathrm{g} / \mathrm{m}^{3}$ in February. The percentage increase was $5 \%$. The monthly averaged $\mathrm{NO}_{2}$ concentration decreased in March and April, and the corresponding monthly averaged $\mathrm{O}_{3}$ concentration in the surface cities showed an obvious trend of decreasing initially and then increasing.

In the monthly averaged $\mathrm{NO}_{2}$ concentration of Shanghai, the trends in change in $\mathrm{NO}_{2}$ concentration in the ground monitoring stations and satellite data were similar. $\mathrm{NO}_{2}$ concentrations at the ground monitoring stations declined from February to May, then the decline rate reached its maximum value in March, with a maximum value of $20.64 \mu \mathrm{g} / \mathrm{m}^{3}$. The percentage decline was $40 \%$. Subsequently, the $\mathrm{NO}_{2}$ concentrations returned to normal levels but fluctuated from June to November. Finally, in December, $\mathrm{NO}_{2}$ concentrations dropped again in 2020 compared with those in 2019 because the Shanghai government introduced management measures to prevent the recurrence of the epidemic [37,39]. Regarding the monthly averaged $\mathrm{O}_{3}$ concentration, the rising months in 2020 were February, April, September, and November. The daily averaged $\mathrm{NO}_{2}$ concentration decreased from 15 February to 28 February, from 1 April to 22 April, from 1 September to 11 September, and from 1 November to 15 November.

For the monthly averaged $\mathrm{NO}_{2}$ concentration in Guangzhou, the interval of decrease in 2020 can be divided into three parts: from February to March, from July to August, and from October to December. The maximum decrease was found in December, and the maximum value was $27.16 \mu \mathrm{g} / \mathrm{m}^{3}$. The percentage decline was $40 \%$. The monthly averaged $\mathrm{O}_{3}$ concentration in Guangzhou increased in February and May, and the corresponding daily averaged $\mathrm{NO}_{2}$ concentration decreased from 6 February to 28 February and from 10 May to 21 May. These effects may have been due to the latitude and typhoon because the latitude in Guangzhou is extremely low. 

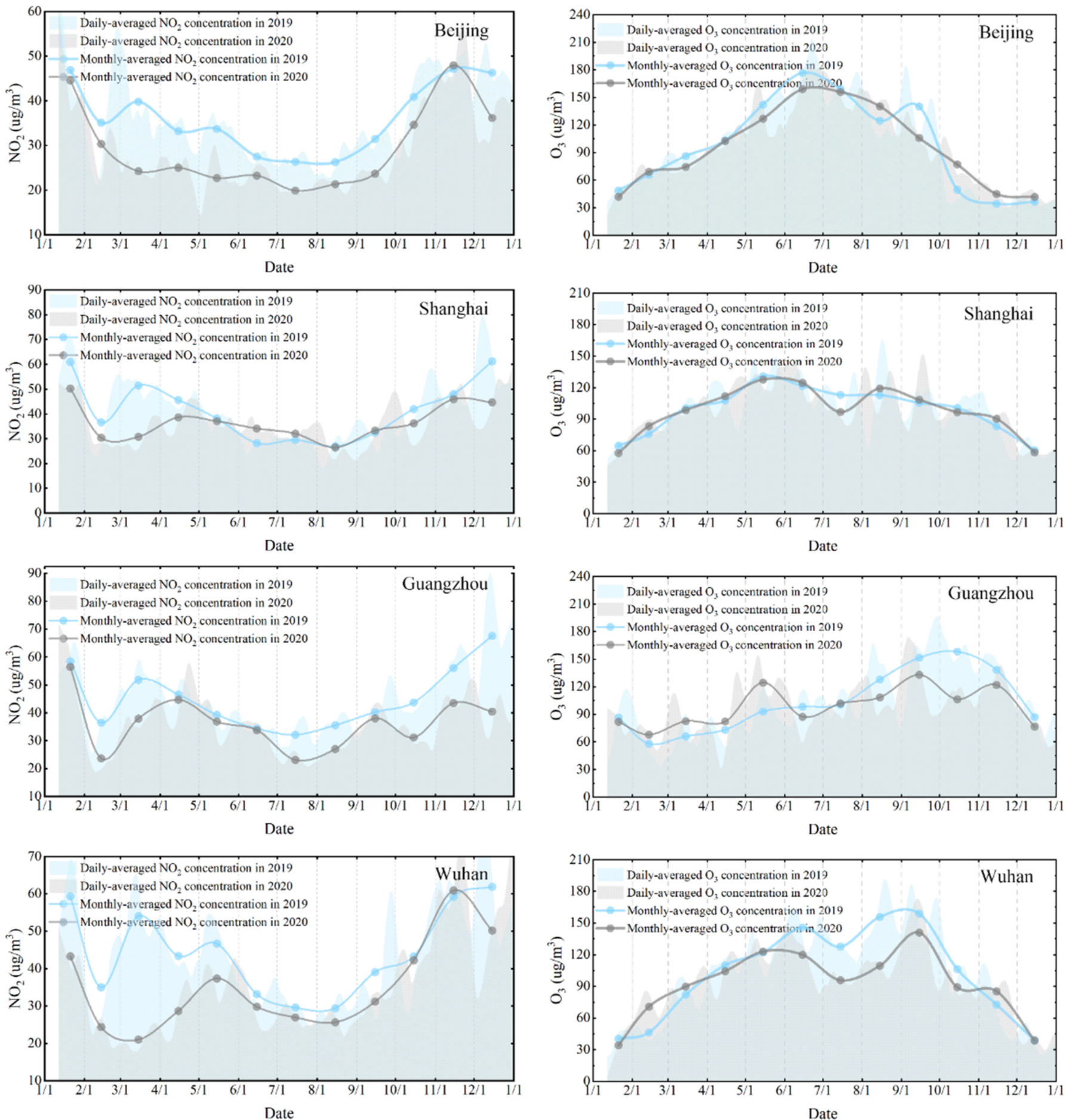

Figure 7. Daily averaged and monthly averaged concentration changes in $\mathrm{NO}_{2}$ and $\mathrm{O}_{3}$ in 2019 and 2020. The blue and gray areas in the figure represent the daily averaged concentrations of $\mathrm{NO}_{2}$ and $\mathrm{O}_{3}$ in 2019 and 2020, respectively. The blue and gray curve represents the monthly averaged concentrations in $\mathrm{NO}_{2}$ and $\mathrm{O}_{3}$ in 2019 and 2020, respectively. We matched the data for 2019 and 2020 according to the Chinese New Year, and the time series in the figure is from 12 January to 31 December.

Wuhan is the first Chinese city to have an epidemic case and, thus, has a long shutdown time. We further analyzed the impact of $\mathrm{NO}_{2}$ and $\mathrm{O}_{3}$ on $\mathrm{XCO}_{2}$ in each month in 2020. Two periods of decrease in the monthly averaged $\mathrm{NO}_{2}$ concentration were found at the ground monitoring stations, namely, from February to May and from December to December. The maximum decrease was found in March, with a maximum value of 
$33.02 \mu \mathrm{g} / \mathrm{m}^{3}$. The percentage decline was $61 \%$. The monthly averaged $\mathrm{O}_{3}$ concentration in Wuhan increased from February to March and from November to November. The daily averaged $\mathrm{NO}_{2}$ concentration first decreased and then increased from 14 February to 27 March. During this period, the monthly averaged $\mathrm{O}_{3}$ concentration was higher than that in the same period in 2019, and the rate of increase in the monthly averaged $\mathrm{O}_{3}$ concentration in March gradually slowed down compared with that in February. We found that the monthly averaged $\mathrm{O}_{3}$ concentration in Wuhan in November 2020 decreased more slowly than that in 2019 and higher than that in 2019. In addition, during this period, the daily averaged $\mathrm{NO}_{2}$ concentration decreased rapidly from 21 November to 30 November, with a value of $32.90 \mu \mathrm{g} / \mathrm{m}^{3}$.

Figure 8 shows the percentage and concentration changes for $\mathrm{O}_{3}$ and $\mathrm{NO}_{2}$ for the four study areas from the satellite observation and the ground monitoring stations observation, respectively. In Figure 8a,b, the maximum monthly averaged concentration changes of $\mathrm{NO}_{2}$ and $\mathrm{O}_{3}$ are shown form satellite observation, respectively. In Figure 8c,d, the maximum monthly averaged concentration changes of $\mathrm{NO}_{2}$ and $\mathrm{O}_{3}$ are shown from ground monitoring stations, respectively. Then, we show the different changes for four cities in each subgraph. For each of the subgraphs, the gray and blue bars represent percentage data and concentration change data, respectively. In general, for the satellite observation estimates, the maximum monthly averaged $\mathrm{NO}_{2}$ concentrations in Beijing, Shanghai, Guangzhou, and Wuhan in February 2020 were $-24 \%\left(-2.52 \times 10^{-5} \mathrm{~mol} / \mathrm{m}^{2}\right),-18 \%$ $\left(-2.32 \times 10^{-5} \mathrm{~mol} / \mathrm{m}^{2}\right),-4 \%\left(-0.25 \times 10^{-5} \mathrm{~mol} / \mathrm{m}^{2}\right)$, and $-39 \%\left(-3.46 \times 10^{-5} \mathrm{~mol} / \mathrm{m}^{2}\right)$, respectively. The corresponding changes in $\mathrm{O}_{3}$ concentration were $5 \%\left(0.85 \times 10^{-2} \mathrm{mg} / \mathrm{m}^{3}\right)$, $14 \%\left(1.55 \times 10^{-2} \mathrm{mg} / \mathrm{m}^{3}\right), 12 \%\left(1.24 \times 10^{-2} \mathrm{mg} / \mathrm{m}^{3}\right)$, and $14 \%\left(1.66 \times 10^{-2} \mathrm{mg} / \mathrm{m}^{3}\right)$. In addition, we further evaluated the monthly averaged data from the daily averaged data in the ground monitoring stations. Surprisingly, the assessment showed that February was not the biggest month of variability in $\mathrm{NO}_{2}$ concentrations from ground monitoring stations. The monthly averaged $\mathrm{NO}_{2}$ concentrations in Beijing, Shanghai, and Wuhan in March had the largest changes, changing to $-39 \%\left(-15.56 \mu \mathrm{g} / \mathrm{m}^{3}\right),-40 \%\left(-20.64 \mu \mathrm{g} / \mathrm{m}^{3}\right)$, and $-61 \%$ $\left(-33.02 \mu \mathrm{g} / \mathrm{m}^{3}\right)$. The corresponding amounts of changes in monthly averaged $\mathrm{O}_{3}$ concentrations were $-14 \%\left(-11.71 \mu \mathrm{g} / \mathrm{m}^{3}\right),-2 \%\left(-1.86 \mu \mathrm{g} / \mathrm{m}^{3}\right)$, and $9 \%\left(-7.63 \mu \mathrm{g} / \mathrm{m}^{3}\right)$. However, the largest amount of change in monthly averaged $\mathrm{NO}_{2}$ concentration in Guangzhou was found in December, with a value of $-40 \%\left(-27.16 \mu \mathrm{g} / \mathrm{m}^{3}\right)$. The amount of change in $\mathrm{O}_{3}$ concentration was $-12 \%\left(-10.46 \mu \mathrm{g} / \mathrm{m}^{3}\right)$ in December.
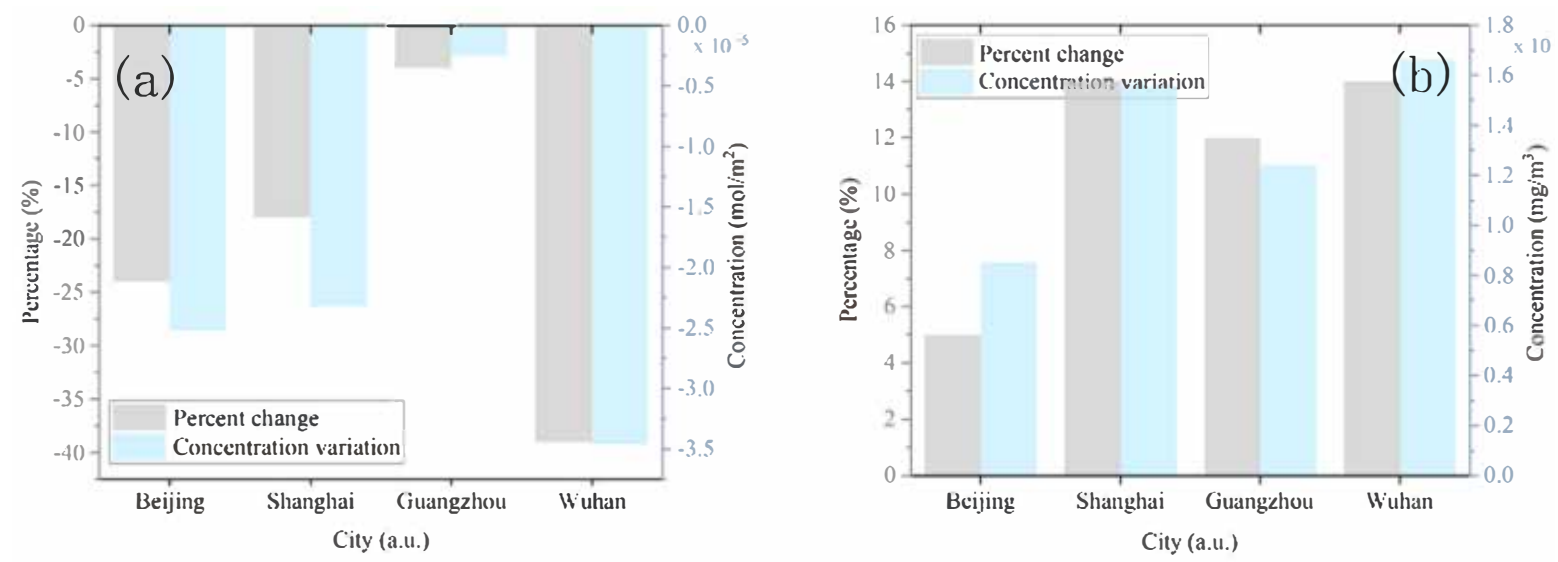

Figure 8. Cont. 

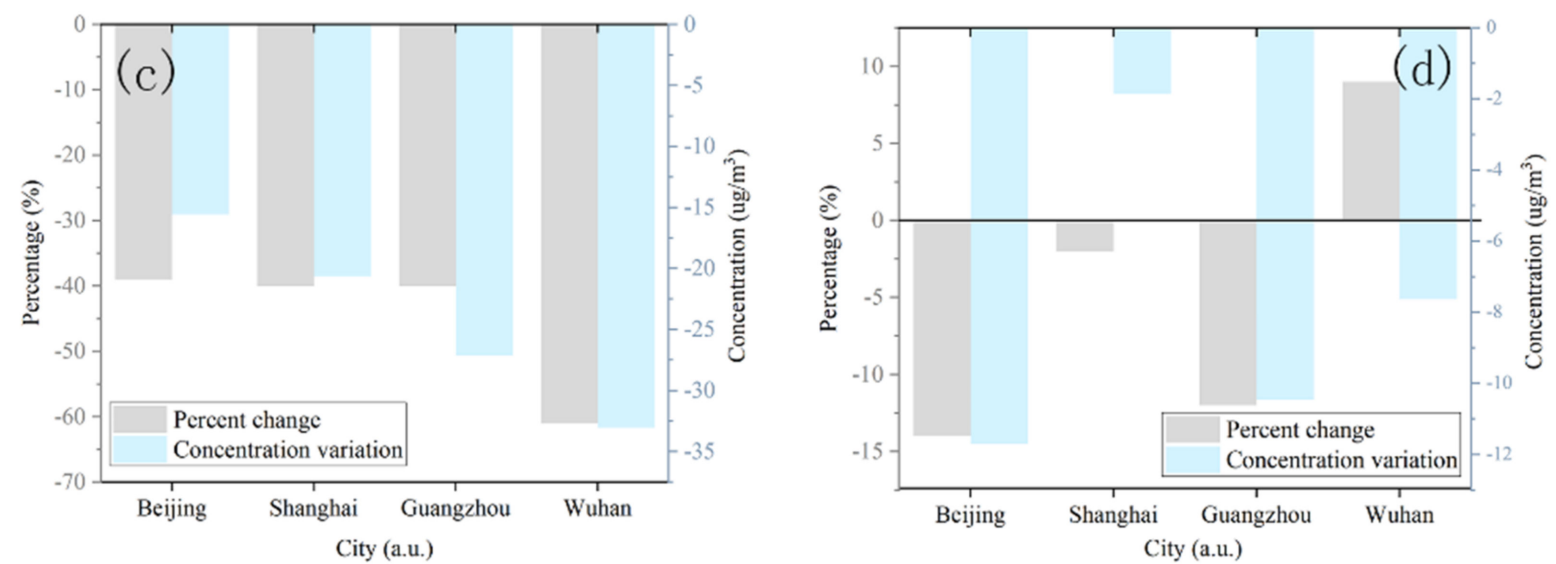

Figure 8. Percentage and concentration changes for $\mathrm{O}_{3}$ and $\mathrm{NO}_{2}$ for the four study areas, respectively. In (a,b), the maximum monthly averaged concentration changes of $\mathrm{NO}_{2}$ and $\mathrm{O}_{3}$ are shown form satellite observation, respectively. In $(\mathbf{c}, \mathbf{d})$, the maximum monthly averaged concentration changes of $\mathrm{NO}_{2}$ and $\mathrm{O}_{3}$ are shown from ground monitoring stations, respectively.

\subsection{The Relation of $\mathrm{NO}_{2}$ and $\mathrm{O}_{3}$ Concentration on $\mathrm{XCO}_{2}$}

From the perspective of satellite and ground monitoring stations observations, we quantitatively show the effect of $\mathrm{NO}_{2}$ concentration and $\mathrm{O}_{3}$ on $\mathrm{XCO}_{2}$ in Figure 9 from top-down and bottom-up. Figure 9 shows the relationship between the monthly averaged variation of $\mathrm{XCO}_{2}$ observed by satellite and the monthly averaged concentration of $\mathrm{NO}_{2}$ and $\mathrm{O}_{3}$ observed by satellite (Figure $9 \mathrm{c}, \mathrm{d}$ ) and ground monitoring stations observations (Figure 9a,b) in February 2020 relative to 2019, respectively. To avoid the error influence of the interpolation theory of $\mathrm{XCO}$, and to accurately reflect the interaction relationship of $\mathrm{XCO}_{2}$ on $\mathrm{NO}_{2}$ and $\mathrm{O}_{3}$ concentration, the $\mathrm{XCO}_{2}$ data were adopted from the original point data of GOSAT_FTS_L3_V2.95 in this chapter, and the data processing theory has not changed. Similarly, we obtained monthly averaged differences in the concentrations of $\mathrm{NO}_{2}, \mathrm{O}_{3}$, and $\mathrm{CO}_{2}$ in February 2020 relative to 2019. We have evaluated a correlation between the variation of $\mathrm{XCO}_{2}$ and the variation of $\mathrm{NO}_{2}$ and $\mathrm{O}_{3}$ in Figure 9. $\mathrm{CO}_{2}$ and NOx emissions derive from industries and traffic. Therefore, a reduction in emissions corresponds to a reduction in concentrations [38,39]. The variations of $\mathrm{XCO}_{2}$ and $\mathrm{NO}_{2}$ should be correlated (as shown in Figure $9 \mathrm{a}, \mathrm{c}$ ), and their correlation coefficients are 0.4912 (from satellite observation) and 0.3928 (from ground station observation), respectively. On the other hand, tropospheric $\mathrm{O}_{3}$ derives from nonlinear photochemical reactions of the NOx and VOC precursors. Thus, a reduction in $\mathrm{NO}_{2}$ can even cause an increase in $\mathrm{O}_{3}$. For this reason, it is possible that $\mathrm{XCO}_{2}$ and $\mathrm{O}_{3}$ (ground stations) are correlated, with a correlation coefficient of -0.3333 .
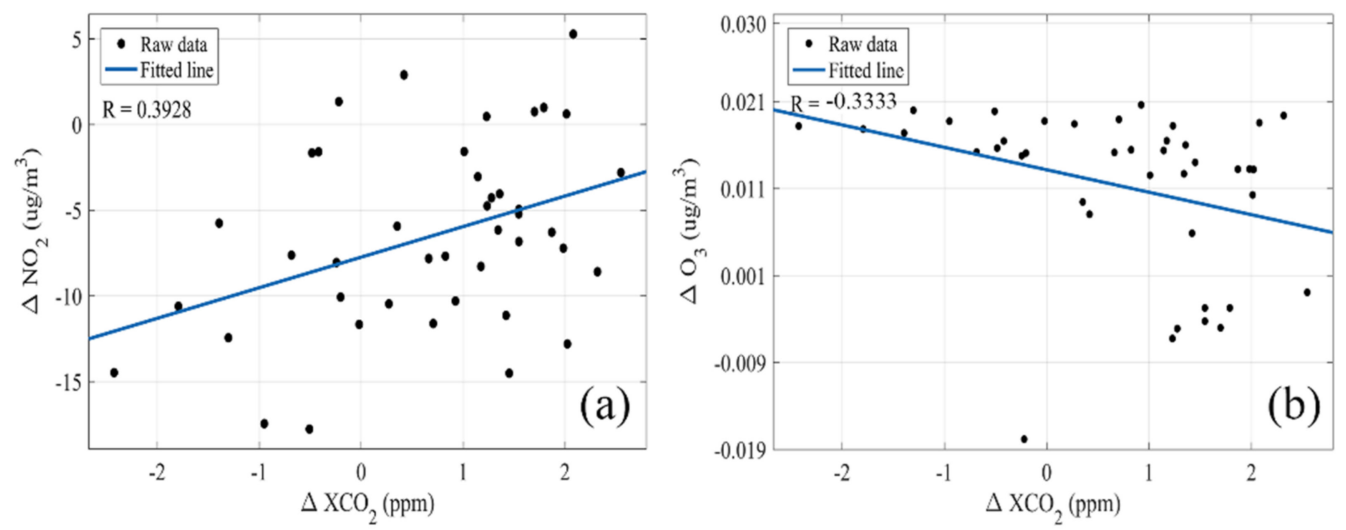

Figure 9. Cont. 

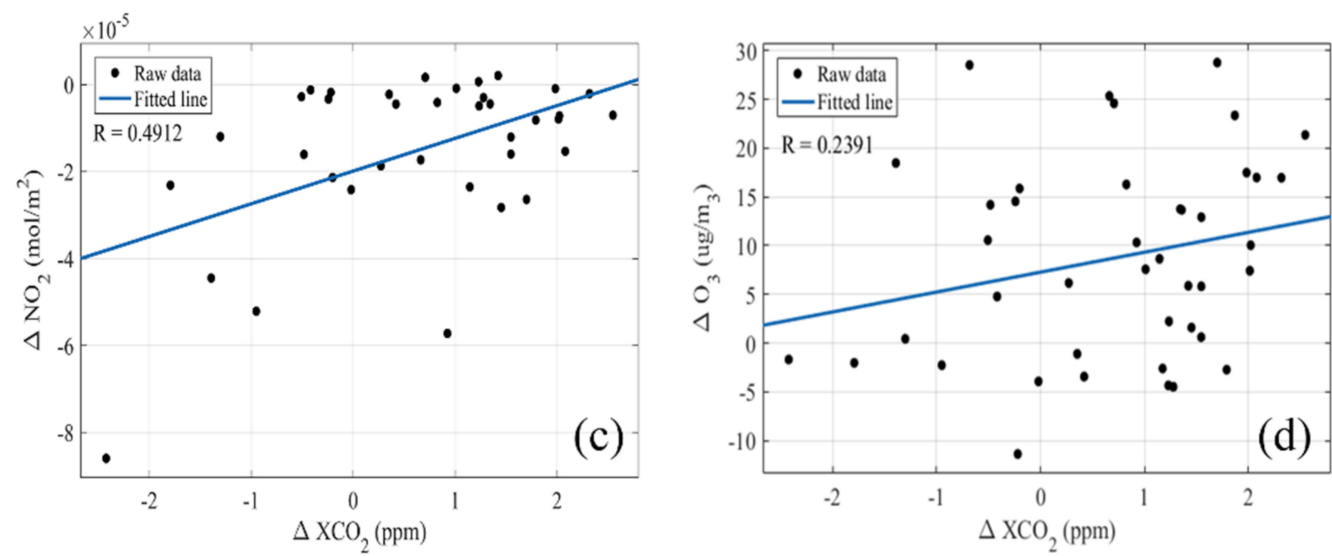

Figure 9. Relationship between the monthly averaged variation of $\mathrm{XCO}_{2}$ observed by satellite and the monthly averaged concentration of $\mathrm{NO}_{2}$ and $\mathrm{O}_{3}$ observed by satellite $(\mathbf{c}, \mathbf{d})$ and ground monitoring stations observations (a,b) in February 2020 relative to 2019, respectively. Restricted by the matching of ground monitoring stations data and GOSAT_FTS_L3_V2.95 data, we retained part of GOSAT_FTS_L3_V2.95 point data.

From the point of promoting the reduction in $\mathrm{XCO}_{2}$ in atmosphere, the contribution of $\mathrm{NO}_{2}$ concentration is greater than that of $\mathrm{O}_{3}$ concentration. However, the relationship between $\mathrm{O}_{3}$ concentration and aerosols was strong because of photochemical reactions [41,42]. Therefore, we can regulate the concentration of $\mathrm{O}_{3}$ by improving the aerosol. In general, from both top-down and bottom-up perspectives, we conclude that we can further improve carbon emissions by regulating $\mathrm{NO}_{2}$ concentrations, but $\mathrm{O}_{3}$ has a relatively small impact on the improvement of $\mathrm{XCO}_{2}$.

\section{Conclusions}

In this work, we analyzed abnormal $\mathrm{XCO}_{2}$ changes in Beijing, Shanghai, Guangzhou, and Wuhan in each month in 2020, and combined the Sentinel-5 Precursor Offline Level 3 product and the ground monitoring network to analyze the effects of $\mathrm{NO}_{2}$ and $\mathrm{O}_{3}$ concentrations on changes in $\mathrm{XCO}_{2}$ with top-down and bottom-up methods, respectively. We found significant differences in the monthly averaged concentrations of $\mathrm{CO}_{2}, \mathrm{NO}_{2}$, and $\mathrm{O}_{3}$. For Beijing, Shanghai, Guangzhou, and Wuhan, the results suggested that the amounts of changes in $\mathrm{XCO}_{2}$ were $0.13,-0.99,-0.89$, and $-1.12 \mathrm{ppm}$ in February. Furthermore, the concentrations of $\mathrm{NO}_{2}$ and $\mathrm{O}_{3}$ changed by $-24 \%$ and $5 \%,-18 \%$ and $14 \%,-4 \%$ and $12 \%,-39 \%$ and $14 \%$ by comparing data in February 2019 with the Sentinel-Satellite5 data. Moreover, for Beijing, Shanghai, Guangzhou, and Wuhan, with regard to the ground monitoring network data, the largest amounts of changes in monthly averaged concentration of $\mathrm{NO}_{2}$ and $\mathrm{O}_{3}$ were $-39 \%$ and $14 \%,-40 \%$ and $-2 \%$, and $-61 \%$ and $9 \%$ in February. However, the largest monthly averaged $\mathrm{NO}_{2}$ concentration change in Guangzhou occurred in December, with a value of $-40 \%$. Thus, the $\mathrm{O}_{3}$ concentration change was $-12 \%$ in December.

In addition, we evaluated the relationship between the variation of $\mathrm{XCO}_{2}$ and the variation of $\mathrm{NO}_{2}$ and $\mathrm{O}_{3}$ in Figure 9. $\mathrm{CO}_{2}$ and $\mathrm{NOx}$ emissions derive from industries and traffic. Therefore, a reduction in emissions corresponds to a reduction in concentration [40]. The variations of $\mathrm{XCO}_{2}$ and $\mathrm{NO}_{2}$ should be correlated [43]. Additionally, the results also show that the effect of $\mathrm{NO}_{2}$ concentration on $\mathrm{XCO}_{2}$ is positively correlated from the point of the satellite $(R=0.4912)$ and the point of the ground monitoring stations $(R=0.3928)$. On the other hand, tropospheric $\mathrm{O}_{3}$ derives from nonlinear photochemical reactions of the NOx and VOC precursors. Thus, a reduction in $\mathrm{NO}_{2}$ can even cause an increase in O3. We also found that $\mathrm{XCO}_{2}$ and $\mathrm{O}_{3}$ are correlated, with a correlation coefficient of 0.2391 (from satellite observations) and -0.3333 (from ground monitoring stations). Therefore, from the point of promoting the reduction in $\mathrm{XCO}_{2}$ in atmosphere, the contribution of $\mathrm{NO}_{2}$ concentration is greater than that of $\mathrm{O}_{3}$ concentration. Nevertheless, the relationship between 
$\mathrm{O}_{3}$ concentration and aerosols was strong because of photochemical reactions [41,42]. We can regulate the concentration of $\mathrm{O}_{3}$ by improving the aerosol. These effects improved air quality and the status of the natural environment. At last, the government should consider reducing $\mathrm{XCO}_{2}$ and $\mathrm{NO}_{2}$ concentration at the same time to make a synergistic reduction.

Author Contributions: Conceptualization, X.M., G.H. and W.G.; methodology, X.M., H.Z. and G.H.; software, X.M., H.Z., H.X. and T.S.; validation, H.Z.; formal analysis, H.Z. and T.S.; data curation, X.M. and G.H.; writing original draft preparation, X.M., W.Z. and H.Z.; supervision, X.M. All authors have read and agreed to the published version of the manuscript.

Funding: This work was supported by the National Natural Science Foundation of China (Grant No. 42171464, 41971283, 41801261, 41827801, 41801282), the National Key Research and Development Program of China (2017YFC0212600), Postdoctoral Science Foundation of China (2017T100580), the Open Research Fund of CAS Key Laboratory of Spectral Imaging Technology, grant number LSIT201917W, the Open Research Fund of National Earth Observation Data Center, grant number NODAOP2021005, and the LIESMARS Special Research Funding.

Acknowledgments: We thank the members of the GOSAT Project for providing us with the GOSAT L3 data products. And We appreciate the validation data from the TCCON (Hefei: https://data. caltech.edu/records/1092). We appreciate the Sentinel-5 data from European Space Agency (https: / / developers.google.com/earthengine/datasets/catalog), and we also appreciate the data from the Chinese ground monitoring network (https://www.aqistudy.cn/historydata/).

Conflicts of Interest: The authors declare no conflict of interest.

\section{References}

1. WHO. Coronavirus Disease (COVID-19) Outbreak Situation World Health Organization. 2020. Available online: https://www. who.int/emergencies/diseases/novel-coronavirus-2019 (accessed on 10 July 2020).

2. Petit, J.-R.; Raynaud, D. Forty years of ice-core records of $\mathrm{CO}_{2}$. Nature 2020, 579, 505-506. [CrossRef] [PubMed]

3. Le Quéré, C.; Jackson, R.B.; Jones, M.W.; Smith, A.; Abernethy, S.; Andrew, R.M.; De-Gol, A.J.; Willis, D.R.; Shan, Y.; Canadell, J.G.; et al. Temporary reduction in daily global $\mathrm{CO}_{2}$ emissions during the COVID-19 forced confinement. Nat. Clim. Chang. 2020, 10, 647-653. [CrossRef]

4. Zhu, Y.; Xie, J.; Huang, F.; Cao, L. Association between short-term exposure to air pollu tion and COVID-19 infection: Evidence from China. Sci. Total Environ. 2020, 727, 138704. [CrossRef]

5. International Energy Agency (IEA). Global Energy Review. IEA: Pari, France. 2020. Available online: https:/ /www.iea.org/ reports/global-energy-review-2020 (accessed on 2 September 2021).

6. Mahato, S.; Pal, S.; Ghosh, K.G. Effect of lockdown amid COVID-19 pandemic on air quality of the megacity Delhi, India. Sci. Total Environ. 2020, 730, 139086. [CrossRef]

7. Otmani, A.; Benchrif, A.; Tahri, M.; Bounakhla, M.; Chakir, E.M.; El Bouch, M.; Krombi, M.H. Impact of COVID-19 lockdown on PM10, $\mathrm{SO}_{2}$ and $\mathrm{NO}_{2}$ concentrations in Salé City (Morocco). Sci. Total Environ. 2020, 735, 139541. [CrossRef] [PubMed]

8. Sharma, S.; Zhang, M.; Gao, J.; Zhang, H.; Kota, S.H. Effect of restricted emissions during COVID-19 on air quality in India. Sci. Total Environ. 2020, 728, 138878. [CrossRef] [PubMed]

9. Wang, P.; Chen, K.; Zhu, S.; Wang, P.; Zhang, H. Severe air pollution events not avoided by reduced anthropogenic activities during COVID-19 outbreak. Resour. Conserv. Recycl. 2020, 158, 104814. [CrossRef]

10. Pei, Z.; Han, G.; Ma, X.; Su, H.; Gong, W. Response of major air pollutants to COVID-19 lockdowns in China. Sci. Total. Environ. 2020, 743, 140879. [CrossRef] [PubMed]

11. Dantas, G.; Siciliano, B.; França, B.B.; da Silva, C.M.; Arbilla, G. The impact of COVID-19 partial lockdown on the air quality of the city of Rio de Janeiro, Brazil. Sci. Total Environ. 2020, 729, 139085. [CrossRef] [PubMed]

12. Şahin, M. Impact of weather on COVID-19 pandemic in Turkey. Sci. Total Environ. 2020, 728, 138810. [CrossRef] [PubMed]

13. Ogen, $\mathrm{Y}$. Assessing nitrogen dioxide $\left(\mathrm{NO}_{2}\right)$ levels as a contributing factor to coronavirus (COVID-19) fatality. Sci. Total Environ. 2020, 726, 138605. [CrossRef] [PubMed]

14. Shi, P.; Dong, Y.; Yan, H.; Zhao, C.; Li, X.; Liu, W.; He, M.; Tang, S.; Xi, S. Impact of temperature on the dynamics of the COVID-19 outbreak in China. Sci. Total. Environ. 2020, 728, 138890. [CrossRef] [PubMed]

15. Buchwitz, M.; Reuter, M.; Noël, S.; Bramstedt, K.; Schneising, O.; Hilker, M.; Andrade, B.F.; Bovensmann, H.; Burrows, J.P.; Di Noia, A.; et al. Can a regional-scale reduction of atmospheric $\mathrm{CO}_{2}$ during the COVID-19 pandemic be detected from space? A case study for East China using satellite $\mathrm{XCO}_{2}$ retrievals. Atmos. Meas. Tech. 2021, 14, 2141-2166. [CrossRef]

16. Yusup, Y.; Kayode, J.S.; Ahmad, M.I.; Yin, C.S.; Hisham, M.S.M.N.; Lsa, H.M. Atmospheric $\mathrm{CO}_{2}$ and total electricity production before and during the nation-wide restriction of activities as a consequence of the COVID-19 pandemic. arXiv 2020, arXiv:2006.04407. 
17. Mitra, A.; Ray Chadhuri, T.; Mitra, A.; Pramanick, P.; Zaman, S. Impact of COVID-19 related shutdown on atmospheric carbon dioxide level in the city of Kolkata. Parana J. Sci. Educ. 2020, 6, 84-92.

18. Xie, X.; Wang, T.; Yue, X.; Li, S.; Zhuang, B.; Wang, M. Effects of atmospheric aerosols on terrestrial carbon fluxes and $\mathrm{CO}_{2}$ concentrations in China. Atmos. Res. 2020, 237, 104859. [CrossRef]

19. Shi, T.; Ma, X.; Han, G.; Xu, H.; Qiu, R.; He, B.; Gong, W. Measurement of $\mathrm{CO}_{2}$ rectifier effect during summer and winter using ground-based differential absorption LiDAR. Atmos. Environ. 2019, 220, 117097. [CrossRef]

20. Han, G.; Ma, X.; Liang, A.; Zhang, T.; Zhao, Y.; Zhang, M.; Gong, W. Performance Evaluation for China's Planned CO 2 -IPDA. Remote Sens. 2017, 9, 768. [CrossRef]

21. Zhong, Y.; Wang, X.; Wang, S.; Zhang, L. Advances in spaceborne hyperspectral remote sensing in China. Geo Spat. Inf. Sci. 2021, 24, 95-120. [CrossRef]

22. Dong, Y.; Liang, T.; Zhang, Y.; Du, B. Spectral-Spatial Weighted Kernel Manifold Embedded Distribution Alignment for Remote Sensing Image Classification. IEEE Trans. Cybern. 2021, 51, 3185-3197. [CrossRef]

23. Jos van Geffen, K.; Boersma, K.F.; Eskes, H.; Sneep, M.; ter Linden, M.; Zara, M.; Veefkind, J.P. S5P/TROPOMI NO 2 slant column retrieval: Method, stability, uncertainties, and comparisons against OMI. Atmos. Meas. Tech. Discuss. 2019, 13, 1315-1335. [CrossRef]

24. GEE. Available online: https://developers.google.com/earthengine/datasets/catalog (accessed on 2 September 2021).

25. GOSATData. Available online: https://data2.gosat.nies.go.jp/GosatDataArchiveService/usr/download/ProductPage/view (accessed on 2 September 2021).

26. GOSAT Instruments and Observational Methods. Available online: https://www.gosat.nies.go.jp/en/about_\%ef\%bc\%92 _observe.html (accessed on 2 September 2021).

27. China Air Quality Network. Available online: https://www.aqistudy.cn/historydata/ (accessed on 2 September 2021).

28. Liu, C.; Wang, W.; Sun, Y. TCCON Data from Hefei, China, Release GGG2014R0, TCCON Data Archive, Hosted by Caltech DATA; California Institute of Technology: Pasadena, CA, USA, 2018. [CrossRef]

29. TCCON Data from Hefei. Available online: https://data.caltech.edu/records/1092 (accessed on 2 September 2021).

30. Ma, X.; Zhang, H.; Han, G.; Mao, F.; Xu, H.; Shi, T.; Hu, H.; Sun, T.; Gong, W. A Regional Spatiotemporal Downscaling Method for $\mathrm{CO}_{2}$ Columns. IEEE Trans. Geosci. Remote Sens. 2021, 1-10. [CrossRef]

31. Gribov, A.; Krivoruchko, K. New flexible non-parametric data transformation for trans-Gaussian kriging. Geostat. Oslo 2012, 17, 51-65.

32. Krivoruchko, K.; Gribov, A. Pragmatic Bayesian kriging for nonstationary and moderately non-Gaussian data. In Mathematics of Planet Earth; Springer: Berlin/Heidelberg, Germany, 2013; Volume 4, pp. 61-64.

33. Pilz, J.; Spöck, G. Why do we need and how should we implement Bayesian kriging methods. Stoch. Environ. Res. Risk Assess. 2007, 22, 621-632. [CrossRef]

34. Dlugokencky, E.J.; Mund, J.W.; Crotwell, A.M.; Crotwell, M.J.; Thoning, K.W. Atmospheric Carbon Dioxide Dry Air Mole Fractions from the NOAA GML Carbon Cycle Cooperative Global Air Sampling Network, 1968-2019. Version: 2020-07. 2020. Available online: https:/ / doi.org/10.15138/wkgj-f215 (accessed on 2 September 2021).

35. Guangzhou Municipal Party Committee Deployed Epidemic Prevention and Control Work. 2020. Available online: http: //www.gz.gov.cn/xw/gzyw/content/post_6892412.html (accessed on 2 September 2021).

36. Healthpeople. 2020. Available online: http://health.people.com.cn/n1/2020/1124/c14739-31941753.html (accessed on 2 September 2021).

37. Shanghai. 2020. Available online: http://sh.bendibao.com/news/20201110/233277.shtm (accessed on 2 September 2021).

38. Economic Opera Tion of Wuhan in 2020. 2020. Available online: http://tjj.wuhan.gov.cn/ztzl_49/xwfbh/202102/t20210202_1624 524.shtml (accessed on 2 September 2021).

39. Six Local Cases Have Been Confirmed in Shanghai. 2020. Available online: http://www.chinanews.com/sh/2020/12-22/93680 36.shtml (accessed on 2 September 2021).

40. Chinanews. 2020. Available online: http://www.gov.cn/zhengce/2020-06/07/content_5517737.htm (accessed on 2 September 2021).

41. Shi, C.; Wang, S.; Liu, R.; Zhou, R.; Li, D.; Wang, W.; Li, Z.; Cheng, T.; Zhou, B. A study of aerosol optical properties during ozone pollution episodes in 2013 over Shanghai, China. Atmos. Res. 2015, 153, 235-249. [CrossRef]

42. Shao, P.; An, J.; Xin, J.; Wu, F.; Wang, J.; Ji, D.; Wang, Y. An analysis on the relationship between ground-level ozone and particulate matter in an industrial area in the Yangtze River delta during summertime. Atmos. Sci. 2017, 41, 618-628. (In Chinese)

43. Park, H.; Jeong, S.; Park, H.; Labzovskii, L.D.; Bowman, K.W. An assessment of emission characteristics of Northern Hemisphere cities using spaceborne observations of $\mathrm{CO}_{2}, \mathrm{CO}$, and $\mathrm{NO}_{2}$. Remote Sens. Environ. 2021, 254, 112246. [CrossRef] 